\title{
Changes in Homogeneous degree Caused by Marine Oil Spill
}

\author{
Dongfang Yang ${ }^{1,2, *}$, Qianqian Qin ${ }^{1}$, Dongmei Jing ${ }^{1}$, Dong Lin ${ }^{1}$, Haixia $\mathrm{Li}^{1}$ \\ ${ }^{1}$ Accountancy School, Xijing University, Xi'an 710123, China; \\ ${ }^{2}$ North China Sea Environmental Monitoring Center, SOA, Qingdao 266033, China;
}

\begin{abstract}
Based on the survey data of Jiaozhou Bay waters in May, September and October 1993, this paper studies the surface horizontal distribution of PHC content in Jiaozhou Bay waters. According to the definition, model and classification of Yang Dongfang homogeneity theory of matter content in waters proposed by the author, the calculation results show that in May, in the waters of Jiaozhou Bay, the non-homogeneous column of PHC content was $46.86 \mu \mathrm{g} / \mathrm{L}$, and the homogeneity of PHC content was $8.15 \%$. At this time, the PHC content had non-homogeneity; in September, the non-homogeneous column of PHC content was $6.53 \mu \mathrm{g} / \mathrm{L}$, and the homogeneous was $48.58 \%$, on which the PHC content had a low degree of homogeneity; in October, the non-homogeneous column of PHC content was $0.40 \mu \mathrm{g} / \mathrm{L}$, and the homogeneity was $96.61 \%$, on which the PHC content had a high degree of homogeneity. This shows that in May, in the entire waters of Jiaozhou Bay, there was the only source of marine oil spill transportation, and the PHC content transported was $51.00 \mu \mathrm{g} / \mathrm{L}$, which was relatively high, resulting that the PHC content was unevenly distributed in the entire water body in the bay. In September, in the entire waters of Jiaozhou Bay, there was only the source of marine oil spill transportation, and its PHC content was $12.70 \mu \mathrm{g} / \mathrm{L}$, which was relatively low. In this way, the distribution of PHC content in the entire water body was lowly homogeneous. In October, there was no source of PHC content in the bay, and the PHC content was relatively low. In this way, the distribution of PHC content in the entire water body was highly homogeneous. From May to September, the monthly decline rate of the PHC content from marine oil spill was $9.57 \mu \mathrm{g} / \mathrm{L}$, the monthly decline rate of the non-homogeneous column of PHC content was $10.08 \mu \mathrm{g} / \mathrm{L}$, and the monthly increase rate of the homogeneity of PHC content was $10.10 \%$. From September to October, the monthly decline rate of the PHC content of marine oil spill was $12.70 \mu \mathrm{g} / \mathrm{L}$, the monthly decline rate of the non-homogeneous column of PHC content was $6.13 \mu \mathrm{g} / \mathrm{L}$, and the monthly increase rate of the homogeneity of PHC content was $48.03 \%$. This fully reveals that the PHC content of marine oil spill is the driving force of its non-homogeneity in the water area, while the ocean tides and currents are the driving force of its homogeneity in the water area. Based on this, the author puts forward the theory of homogeneous distribution of material content: under the action of ocean tides and currents, the ocean has the characteristics of homogeneity, and the distribution of material content in the ocean water body shows homogeneity.
\end{abstract}

\section{Introduction}

On the eastern coast of Jiaozhou Bay, it established terminal oil storage base and appeared many oil tankers went to and from Jiaozhou Bay. The occurrence of marine oil spills transported the PHC content to the bay waters[1-6]. Therefore, based on the survey data in 1993, the horizontal distribution and source of PHC in the Jiaozhou Bay water were analyzed, and the definition of Yang Dongfang homogeneity of matter content in waters, model, and classification standards determined the non-homogeneous column and homogeneity of PHC content in the waters of Jiaozhou Bay, which provides a scientific theoretical basis for protecting the marine environment and maintaining ecological sustainable development.

\section{Survey waters, materials and methods}

\subsection{The natural environment of Jiaozhou Bay}

Jiaozhou Bay is located in the southern part of Shandong Peninsula. Its geographical position is between $120^{\circ} 04^{\prime}$ $-120^{\circ} 23^{\prime} \mathrm{E}$ and $35^{\circ} 58^{\prime}-36^{\circ} 18^{\prime} \mathrm{N}$. It is bounded by the line connecting Tuan Island and Xuejia Island, and is connected to the Yellow Sea. With an area of about $446 \mathrm{~km}^{2}$ and an average water depth of about $7 \mathrm{~m}$, it is a typical semi-enclosed bay. the Dagu River, Yang River and the Haibo River, Licun River and Loushan River in Qingdao City with larger runoff and sand content are all seasonal rivers, and the river hydrological characteristics have obvious seasonal changes[7,8].

*dfyang_dfyang@126.com 


\subsection{Materials and methods}

The survey data of PHC content in Jiaozhou Bay in May, September and October 1993 used in this study are provided by the North Sea Monitoring Center of the State Oceanic Administration. Seven stations were set up in Jiaozhou Bay to take water samples: stations H3101, H3102, H3103, H3104, H3105, H3106 and H3107 (Figure 1). Sampling was conducted three times in May, September and October 1993, respectively. Water samples were taken according to the water depth (surface and bottom layers were taken when the depth $>10 \mathrm{~m}$, and only the surface layer the depth $<10 \mathrm{~m}$ ) for investigation and sampling. The survey of PHC content in Jiaozhou Bay water body was carried out by the national standard method, recorded in the national Marine Monitoring Code (1991)[9].

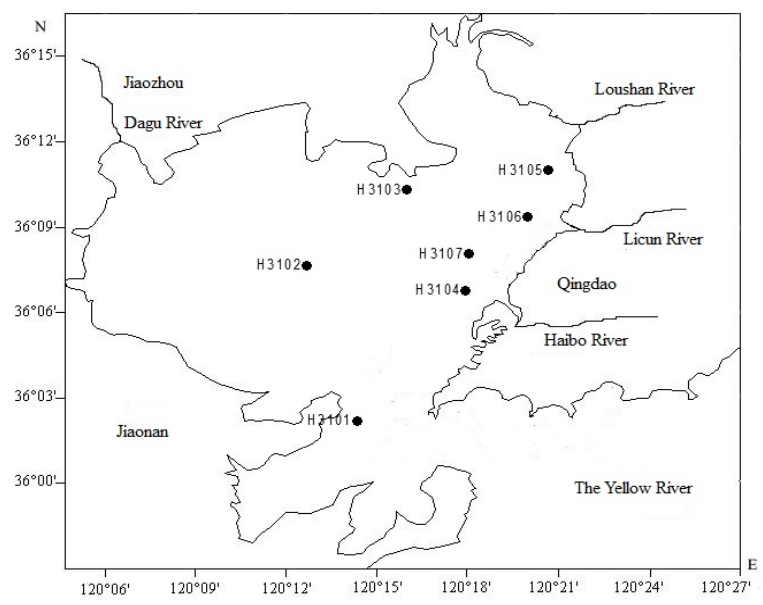

Fig.1 Investigation sites in Jiaozhou Bay

\section{Results}

\subsection{Horizontal distribution in the surface waters}

In May, in the eastern part of Jiaozhou Bay, the PHC content reached a high level of $51.00 \mu \mathrm{g} / \mathrm{L}$ at $\mathrm{H} 3107$ station in the eastern central waters, forming a high content area of PHC with $\mathrm{H} 3107$ station as the center and a series of concentric circles with different gradients. The PHC content decreased from the high content of $51.00 \mu \mathrm{g} / \mathrm{L}$ in the center to the surroundings along the gradient, to $31.60 \mu \mathrm{g} / \mathrm{L}$ in the central waters of the bay, $27.00 \mu \mathrm{g} / \mathrm{L}$ in the northern waters of the bay, and $4.16 \mu \mathrm{g} / \mathrm{L}$ in the waters of the bay mouth (Figure 2).

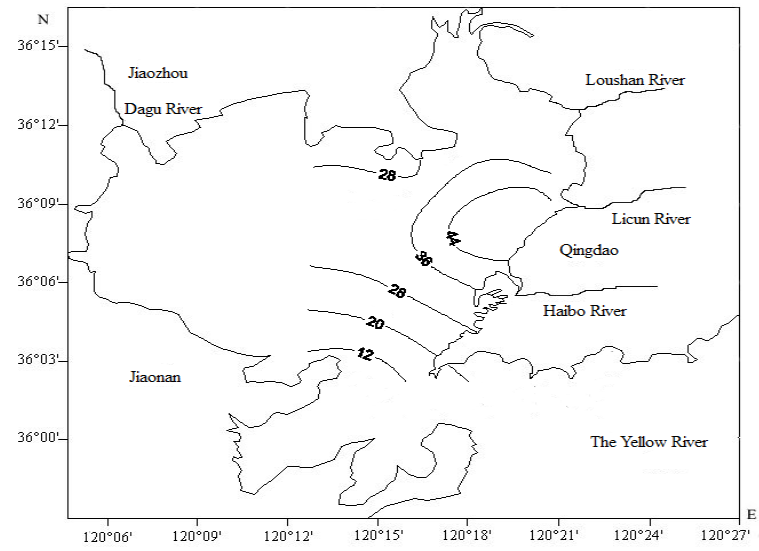

Fig.2 The surface distribution of PHC content in $\operatorname{May}(\mu \mathrm{g} / \mathrm{L})$

In September, in the eastern part of Jiaozhou Bay, the PHC content reached a high level of $12.70 \mu \mathrm{g} / \mathrm{L}$ at $\mathrm{H} 3107$ station in the eastern central waters, forming a high content area of PHC with $\mathrm{H} 3107$ station as the center and a series of concentric circles with different gradients. The PHC content decreased from the high content of $12.70 \mu \mathrm{g} / \mathrm{L}$ in the center along the gradient to the surroundings, to $6.17 \mu \mathrm{g} / \mathrm{L}$ in the northeast waters of the bay, and $11.40 \mu \mathrm{g} / \mathrm{L}$ in the southeast waters of the bay (Figure 3).

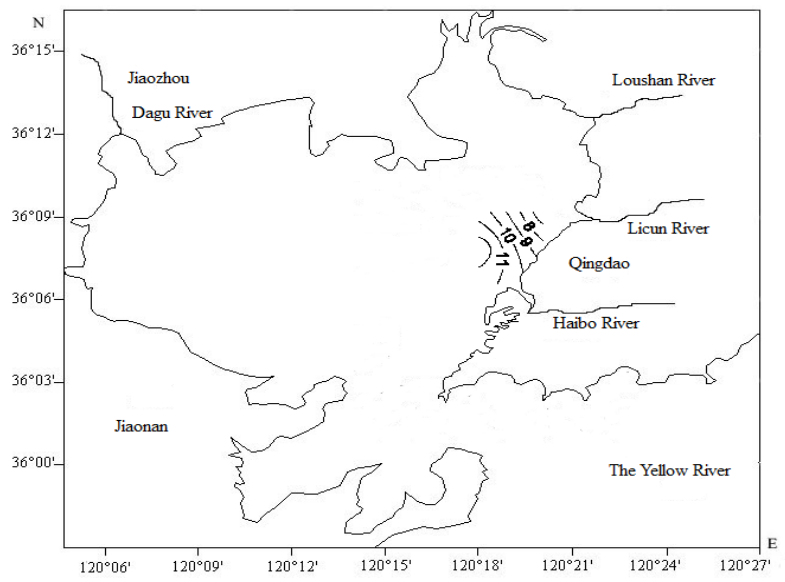

Fig.3 The surface distribution of PHC content in September $(\mu \mathrm{g} / \mathrm{L})$

In October, at $\mathrm{H} 3103$ station in the coastal waters of the north of Jiaozhou Bay, the content of PHC reached a high level of $11.80 \mu \mathrm{g} / \mathrm{L}$, forming a high content area of PHC in the northern coastal waters. Taking the high content area of PHC as the center, it formed a series of parallel lines with different gradients. The content of PHC decreased from the high content of $11.80 \mu \mathrm{g} / \mathrm{L}$ in the center along the gradient to $11.40 \mu \mathrm{g} / \mathrm{L}$ in the southeast coastal waters.

\subsection{Sources}

In May, a high-content area of PHC was formed in the eastern central waters of Jiaozhou Bay, and the PHC content transported declined along the gradient, resulting in a decrease along the gradient to the surrounding area, which indicated that the source of PHC was the 
transportation of marine oil spills, whose PHC content was $51.00 \mu \mathrm{g} / \mathrm{L}$.

In September, a high-content area of PHC was formed in the eastern central waters of Jiaozhou Bay, and the transported PHC content declined along the gradient, resulting in a decrease along the gradient to the surroundings, which indicated that the source of PHC was the transportation of marine oil spills, whose PHC content was $12.70 \mu \mathrm{g} / \mathrm{L}$.

In October, the change of PHC content does not exceed $0.50 \mu \mathrm{g} / \mathrm{L}$ from the northern coastal waters of Jiaozhou Bay to the southeastern coastal waters, which indicated that in the waters of Jiaozhou Bay, the PHC content was uniform, and there was almost no source to transport PHC.

Therefore, the PHC content in the waters of Jiaozhou Bay had only one source, which was mainly from the transportation of marine oil spill (Table 1). The PHC content from marine oil spill was $12.70-51.00 \mu \mathrm{g} / \mathrm{L}$.

Table 1 The PHC contents from only one source in Jiaozhou bay

\begin{tabular}{|c|c|}
\hline The only source & Transportation of marine oil spill \\
\hline PHC content $/ \mu \mathrm{g} \cdot \mathrm{L}-1$ & $12.70-51.00$ \\
\hline
\end{tabular}

\subsection{Matter content variation length model}

The author proposed the definition and model of Yang Dongfang homogeneity of matter content in waters. The Yang Dongfang homogeneity of matter content in waters is defined as the difference degree between the high value and low value of matter content in waters. The less the difference, the better the homogeneity; the greater the difference, the worse the homogeneity. Here we use two concepts proposed by Yang Dongfang, non-homogeneous column of matter content in waters and homogeneity of matter content in waters, to describe the homogeneous degree of matter content in waters. Non-homogeneous column of matter content in waters refers to the difference between high value and low value of matter content in waters. Homogeneous degree of matter content in waters refers to the percentage of the ratio of the low value to the high value of matter content in waters.

The author proposed the homogeneity model of matter content in waters, which is composed of the non-homogeneous column model of matter content in waters and homogeneous degree model of matter content in waters.

Assuming that the variation range of matter content in waters is: $a-b \mu g / L, 0 \leq a \leq b$, and if $a=b$, there is $0<a=b$.

Non-homogeneous column model of matter content in waters is: $\mathrm{YFJYZ}=\mathrm{b}-\mathrm{a}(\mu \mathrm{g} / \mathrm{L})(1)$

Homogeneous degree model of matter content in waters is: $Y J Y D=a / b \%(2)$

The model of homogeneity of matter content in waters can be described as follows: 1. the range of variation of matter content; 2 . the homogeneity of matter content in waters.

If the length of non-homogeneous column becomes greater, it indicates that the matter content in the waters becomes more and more non-homogeneous. If the length of non-homogeneous column becomes less, it indicates that the matter content in the waters becomes more and more homogeneous.

If the homogeneous degree becomes less and less, it indicates that the matter content in waters becomes more and more non-homogeneous. When $\mathrm{a}=0, \mathrm{YJYD}=0$, the homogeneous degree is 0 , which is the smallest. If the homogeneous degree becomes larger and larger, it indicates that the matter content in waters becomes more and more homogeneous. When $a=b, Y J Y D=1$, the homogeneous degree is 1 , which is the biggest. Therefore, $0 \leq \mathrm{YJYD} \leq 1$.

\subsection{Classification standard of homogeneous degree}

According to the homogeneous degree proposed by the author, if the homogeneous degree of matter content in waters becomes less and less, the matter content in waters becomes more and more non-homogeneous; if the homogeneous degree of matter content in waters becomes larger and larger, the matter content in waters becomes more and more homogeneous. Table 2 shows the classification standard of Yang Dongfang homogeneous degree of matter content in waters.

Table 2 The classification standard of matter content homogeneous degree

\begin{tabular}{|c|c|c|c|}
\hline $\begin{array}{l}\text { Homogeneous } \\
\text { Degree (YJYD) }\end{array}$ & $\begin{array}{l}\text { Homogeneous } \\
\text { Degree } \\
\text { Discription } \\
\end{array}$ & $\begin{array}{l}\text { Non-homogeneous } \\
\text { column (YFJYZ) }\end{array}$ & $\begin{array}{l}\text { Parameters: } \\
\text { a, b }\end{array}$ \\
\hline YJYD $=0$ & \begin{tabular}{|l|} 
Most non \\
-homogeneous
\end{tabular} & YFJYZ=b & $a=0$ \\
\hline $0<\mathrm{YJYD} \leq 30 \%$ & $\begin{array}{l}\text { Non } \\
\text {-homogeneous }\end{array}$ & $0.7 \mathrm{~b} \leq \mathrm{YFJYD}<\mathrm{b}$ & $\begin{array}{l}\mathrm{a}=0.3 \mathrm{~b}, \\
\text { when } \\
\text { YJYD }=30 \%\end{array}$ \\
\hline $30 \%<$ YJYD $\leq 60 \%$ & $\begin{array}{l}\text { Low } \\
\text { homogeneous }\end{array}$ & $0.4 \mathrm{~b} \leq \mathrm{YFJYD}<0.7 \mathrm{~b}$ & $\begin{array}{l}\mathrm{a}=0.6 \mathrm{~b}, \\
\text { when } \\
\text { YJYD }=60 \%\end{array}$ \\
\hline $60 \%<$ YJYD $\leq 90 \%$ & $\begin{array}{l}\text { Significantly } \\
\text { homogeneous }\end{array}$ & $0.1 \mathrm{~b} \leq$ YFJYD $<0.4 b$ & $\begin{array}{l}\mathrm{a}=0.9 \mathrm{~b}, \\
\text { when } \\
\text { YJYD }=90 \%\end{array}$ \\
\hline $90 \%<$ YJYD $\leq 99 \%$ & $\begin{array}{l}\text { Highly } \\
\text { homogeneous }\end{array}$ & $0.01 b \leq$ YFJYD $<0.1 b$ & $\begin{array}{l}\mathrm{a}=0.99 \mathrm{~b}, \\
\text { when } \\
\text { YJYD }=99 \%\end{array}$ \\
\hline YJYD $=100 \%$ & $\begin{array}{l}\text { Most } \\
\text { homogeneous }\end{array}$ & YFJYZ $=0$ & $a=b$ \\
\hline
\end{tabular}

The classification standard of matter content homogeneous degree quantitively reveals the homogeneous degree of matter content. Thus, whether the matter content is homogeneous or not and how about the homogeneous degree will be very obvious based on this classification standard. The homogeneous degree of any matter content in waters will be presented quantitively.

\subsection{Application of homogeneous variation model}

In May, the variation range of PHC content in the waters inside Jiaozhou Bay is $4.16-51.00 \mu \mathrm{g} / \mathrm{L}$; in September, the variation range of $\mathrm{PHC}$ content in the waters inside Jiaozhou Bay is $6.17-12.70 \mu \mathrm{g} / \mathrm{L}$; in October, the variation range of $\mathrm{PHC}$ content in the waters inside 
Jiaozhou Bay is $11.40-11.80 \mu \mathrm{g} / \mathrm{L}$. Therefore, in the waters inside Jiaozhou Bay in May, the non-homogeneous column of PHC content is $46.86 \mu \mathrm{g} / \mathrm{L}$ and the homogeneous degree is $8.15 \%$. The PHC content is non-homogeneous. In September, the non-homogeneous column of PHC content is $6.53 \mu \mathrm{g} / \mathrm{L}$ and the homogeneous degree of PHC content is $48.58 \%$. The PHC content is lowly homogeneous. In October, the non-homogeneous column of PHC content is $0.40 \mu \mathrm{g} / \mathrm{L}$ and the homogeneous degree is $96.61 \%$. At this time, the PHC content is high homogeneous (Table 3).

Table 3 The non-homogeneous column and homogeneous degree of PHC content in May, September and October in Jiaozhou Bay $(\mu \mathrm{g} \cdot \mathrm{L}-1)$

\begin{tabular}{|l|c|c|c|}
\hline Time & May & September & October \\
\hline $\begin{array}{l}\text { Transported by } \\
\text { marine oil spill }\end{array}$ & 51.00 & 12.70 & 0.00 \\
\hline $\begin{array}{l}\text { Non-homogeneous } \\
\text { column of PHC }\end{array}$ & 46.86 & 6.53 & 0.40 \\
\hline $\begin{array}{l}\text { Homogeneous } \\
\text { degree of PHC }\end{array}$ & $8.15 \%$ & $48.58 \%$ & $96.61 \%$ \\
\hline $\begin{array}{l}\text { Homogeneity } \\
\text { Description }\end{array}$ & $\begin{array}{l}\text { Non } \\
\text {-homogeneous }\end{array}$ & $\begin{array}{c}\text { Lowly } \\
\text { homogeneous }\end{array}$ & $\begin{array}{c}\text { Highly } \\
\text { Homogeneous }\end{array}$ \\
\hline
\end{tabular}

The PHC content in the waters of Jiaozhou Bay only has one source, which is the transportation of marine oil spill. In May, the PHC content from marine oil spill is $51.00 \mu \mathrm{g} / \mathrm{L}$. In September, it is $12.70 \mu \mathrm{g} / \mathrm{L}$. And in October, it is $0.00 \mu \mathrm{g} / \mathrm{L}$. Therefore, the PHC content in the waters of Jiaozhou Bay from marine oil spill has great influence on the homogeneity of PHC in the waters inside the bay.

\section{Discussion}

\subsection{Homogeneity of the ocean}

The author proposed that the ocean tides and currents stir all the matter content in the ocean waters and transport them so that all the matter content in the ocean bodies is evenly distributed. In the nearshore shallow waters, it mainly relies on the tides; while in the deep sea, it mainly relies on the ocean currents. Of course, there are still other subsidiary effects, such as storm tides, seaquake, etc. Therefore, along the time changes, the ocean makes all the matter content in the waters distribute evenly as far as possible. So the ocean has homogeneity.

The spatial and temporal changes of the horizontal distribution of PHC content in the waters of Jiaozhou Bay in 1993 fully presents that under the effect of transportation from sources, the PHC content is continuously input in the waters and shows a variation process from non-homogeneous to homogeneous.

\subsection{The process of uniform changes in space}

Matter content has homogeneity and non-homogeneity. According to the definition, model and classification of Yang Dongfang homogeneity of matter content in waters, this paper sufficiently and quantitively presents the variation process of matter content in space.
In May, the variation range of PHC content in the entire waters was $4.16-51.00 \mu \mathrm{g} / \mathrm{L}$. A high-content area of PHC was formed in the eastern central waters of Jiaozhou Bay, and the PHC content transported declined along the gradient, resulting in a decrease along the gradient to the surrounding area, which indicated that the source of PHC was the transportation of marine oil spills, whose PHC content was $51.00 \mu \mathrm{g} / \mathrm{L}$, relatively high (Figure 2). According to the definition, model and classification of Yang Dongfang homogeneity of matter content in waters, it can be calculated that the non-homogeneous column of PHC content is $46.86 \mu \mathrm{g} / \mathrm{L}$ and its homogeneous degree is $8.15 \%$. The PHC content is non-homogeneous. It fully presents the PHC content in entire water body is non-homogeneous, which is because the transportation of marine oil spill, the only source of PHC content, delivered a relatively high-level content.

In September, the variation range of PHC content in the entire waters was $6.17-12.70 \mu \mathrm{g} / \mathrm{L}$. A high-content area of PHC was formed in the eastern central waters of Jiaozhou Bay, and the PHC content transported declined along the gradient, resulting in a decrease along the gradient to the surrounding area, which indicated that the source of PHC was the transportation of marine oil spills, whose PHC content was $12.70 \mu \mathrm{g} / \mathrm{L}$, relatively low (Figure 3). According to the definition, model and classification of Yang Dongfang homogeneity of matter content in waters, it can be calculated that the non-homogeneous column of PHC content is $6.53 \mu \mathrm{g} / \mathrm{L}$ and its homogeneous degree is $48.58 \%$. The PHC content is lowly homogeneous. It fully presents the distribution of PHC content in entire water body is low-homogeneous, which is because the transportation of marine oil spill, the only source of PHC content, delivered a relatively low-level content.

In October, the variation range of PHC content in the entire waters was $11.40-11.80 \mu \mathrm{g} / \mathrm{L}$, which indicated the PHC content is relatively low in the entire waters of Jiaozhou Bay and there is no any source of PHC content inside the bay. Thus, the variation range of PHC content is very small. According to the definition, model and classification of Yang Dongfang homogeneity of matter content in waters, it can be calculated that the non-homogeneous column of PHC content is $0.40 \mu \mathrm{g} / \mathrm{L}$ and its homogeneous degree is $96.61 \%$. The PHC content has high homogeneity. It fully presents the PHC content in entire water body is evenly distributed.

\subsection{The process of uniform changes in time}

In May, the PHC content transported by marine oil spill to the eastern costal waters of Jiaozhou Bay was relatively high. In the entire water body, the distribution of PHC was uneven. In September, the PHC content transported by marine oil spill to the eastern coastal waters of Jiaozhou Bay was relatively low. In the entire water body, the distribution of PHC had low-homogeneity. In October, there was no any source of PHC content and its distribution has high-homogeneity.

In the entire water body of Jiaozhou Bay, the distribution of PHC content was non-homogeneous in 
May, low-homogeneous in September and high-homogeneous in October. Therefore, the PHC content from the transportation of marine oil spill decreased from $51.00 \mu \mathrm{g} / \mathrm{L}$ to $12.70 \mu \mathrm{g} / \mathrm{L}$ from May to September, the homogeneity of PHC content changed from non-homogeneous distribution to low-homogeneous distribution. The non-homogeneous distribution of PHC content was caused by the changes of PHC content transported from marine oil spill. The PHC content from the transportation of marine oil spill decreased from $12.70 \mu \mathrm{g} / \mathrm{L}$ to $0.00 \mu \mathrm{g} / \mathrm{L}$ from September to October, the homogeneity of PHC content changed from low-homogeneous distribution to high-homogeneous distribution. The high-homogeneous distribution of PHC content was caused by the stir and transportation of ocean tides and currents.

This reveals that the transportation of marine oil spill makes the ocean have non-homogeneity characteristic while the ocean tides and currents make the ocean have the characteristic of homogeneity. As the author pointed out, ocean tides and currents stir all the matter content in the ocean so that they are evenly distributed in the ocean water. Therefore, the variation process of PHC content in the waters presents the characteristic of homogeneous distribution of matters in the ocean.

\subsection{Homogeneous distribution theory of matter content}

In May, the PHC content in the entire waters of Jiaozhou Bay only had one source of the transportation of marine oil spill, whose content was $51.00 \mu \mathrm{g} / \mathrm{L}$, relatively high. It caused the uneven distribution of PHC content in the entire waters. The non-homogeneous column of PHC content was $46.86 \mu \mathrm{g} / \mathrm{L}$ and the homogeneous degree of PHC content was $8.15 \%$.

In September, the PHC content in the entire waters of Jiaozhou Bay only had one source of the transportation of marine oil spill, whose content was $12.70 \mu \mathrm{g} / \mathrm{L}$, relatively low. It caused the low-homogeneous distribution of PHC content in the entire waters. The non-homogeneous column of PHC content was $6.53 \mu \mathrm{g} / \mathrm{L}$ and the homogeneous degree of PHC content was $48.58 \%$.

In October, the PHC content in the entire waters of Jiaozhou Bay was relatively low. There was no any source of PHC content. Thus, the variation range of PHC content was very small. In the entire waters of bay, the distribution of PHC content in the waters was highly homogeneous. The non-homogeneous column of PHC content was $0.40 \mu \mathrm{g} / \mathrm{L}$ and the homogeneous degree of PHC content was $96.61 \%$.

From May to September, the monthly decline rate of the PHC content from marine oil spill was $9.57 \mu \mathrm{g} / \mathrm{L}$, the monthly decline rate of the non-homogeneous column of PHC content was $10.08 \mu \mathrm{g} / \mathrm{L}$, and the monthly increase rate of the homogeneous degree of PHC content was $10.10 \%$ (Figure 4).

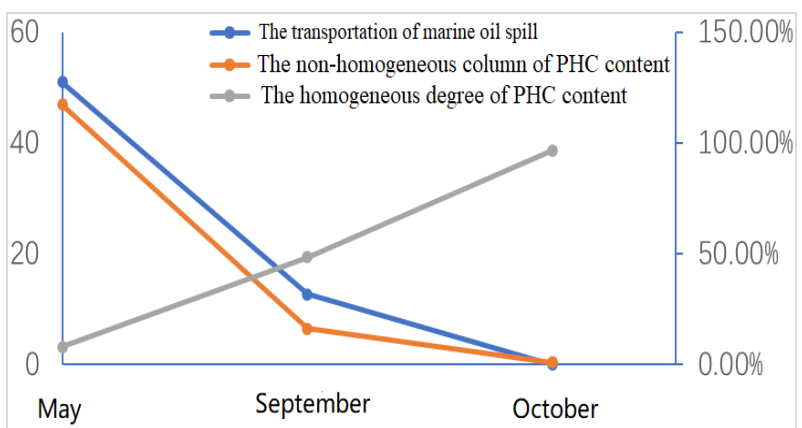

Fig.4 PHC content transported by marine oil spill and its non-homogeneous column and homogeneous degree $(\mu \mathrm{g} / \mathrm{L})$

From September to October, the monthly decline rate of the PHC content from marine oil spill was $12.70 \mu \mathrm{g} / \mathrm{L}$, the monthly decline rate of the non-homogeneous column of PHC content was $6.13 \mu \mathrm{g} / \mathrm{L}$, and the monthly increase rate of the homogeneous degree of PHC content was $48.03 \%$ (Figure 4 ).

The variation of the monthly decline rate of PHC content from marine oil spill, monthly decline rate of PHC non-homogeneous column and monthly increase rate of PHC homogeneous degree fully reveals that the $\mathrm{PHC}$ content of marine oil spill is the driving force of its non-homogeneity in the water area, while the ocean tides and currents are the driving force of its homogeneity in the water area. In addition, the variation of these three rates further presents the changing process of the ocean homogeneity: from non-homogeneity to homogeneity.

No matter how low the matter content is, the ocean will bring it to more remote place resulting its lower content and homogeneous distribution in the ocean, which fully demonstrates the homogeneity of the ocean [11]. Therefore, the homogeneous distribution theory of matter content proposed by the author believes that the ocean tides and currents make the ocean have the homogeneity characteristic. The distribution of matter content in the ocean water presents homogeneity. Just like the liquid in the container, add materials, and continuously stir and shake will gradually make the liquid distribute evenly with time going on.

\section{Conclusion}

By the definition, model and classification standard of Yang Dongfang homogeneity of matter content in waters, it can be calculated that in the entire waters of Jiaozhou Bay, in May, the non-homogeneous column of PHC content was $46.86 \mu \mathrm{g} / \mathrm{L}$ and the homogeneous degree of PHC content was $8.15 \%$. The PHC was non-homogeneous; in September, the non-homogeneous column of PHC content was $6.53 \mu \mathrm{g} / \mathrm{L}$ and the homogeneous degree of PHC content was $48.58 \%$. The PHC was low-homogeneous; in October, the non-homogeneous column of PHC content was $0.40 \mu \mathrm{g} / \mathrm{L}$ and the homogeneous degree of PHC content was $96.61 \%$. The PHC was high-homogeneous. It presents that in May, the PHC content in the entire waters of Jiaozhou Bay only had one source of the transportation of marine oil spill, whose content was $51.00 \mu \mathrm{g} / \mathrm{L}$, 
relatively high. It caused the uneven distribution of PHC content in the entire waters. In September, the PHC content in the entire waters of Jiaozhou Bay only had one source of the transportation of marine oil spill, whose content was $12.70 \mu \mathrm{g} / \mathrm{L}$, relatively low. It caused the low-homogeneous distribution of PHC content in the entire waters. In October, the PHC content in the entire waters of Jiaozhou Bay was relatively low. There was no any source of PHC content. Thus, the variation range of PHC content was very small. In the entire waters of bay, the distribution of PHC content in the waters was highly homogeneous.

From May to September, the monthly decline rate of the PHC content from marine oil spill was $9.57 \mu \mathrm{g} / \mathrm{L}$, the monthly decline rate of the non-homogeneous column of PHC content was $10.08 \mu \mathrm{g} / \mathrm{L}$, and the monthly increase rate of the homogeneous degree of PHC content was $10.10 \%$. From September to October, the monthly decline rate of the PHC content from marine oil spill was $12.70 \mu \mathrm{g} / \mathrm{L}$, the monthly decline rate of the non-homogeneous column of PHC content was $6.13 \mu \mathrm{g} / \mathrm{L}$, and the monthly increase rate of the homogeneous degree of PHC content was $48.03 \%$. This fully reveals that the PHC content of marine oil spill is the driving force of its non-uniformity in the water area, while the ocean tides and currents are the driving force of its uniformity in the water area. What's more, the rate changes further reveal the variation process of ocean homogeneity: from non-homogeneity to homogeneity. Based on this, the author puts forward the homogeneity theory of matter content in waters: under the action of ocean tides and currents, the ocean has the characteristics of homogeneity, and the distribution of matter content in the ocean water body shows homogeneity

\section{References}

1. Dongfang Yang, Youchi Zhang, Jie Zou, et al. Contents and distribution of petroleum hydrocarbons (PHC) in Jiaozhou Bay waters [J]. Open Journal of
Marine Science, 2011, 2(3): 108-112

2. Dongfang Yang, Peiyan Sun, Chen Chen, Hongyan Bai, Qing Zhou. Pollution Source and Distribution of PHC in the Jiaozhou Bay Waters [J]. Coastal Engineering, 2013, 32(1): 60-72.

3. Dongfang Yang, Peiyan Sun, Lian Ju, Chunhui Wang and Yunlong Liu. Distribution and changing of petroleum hydrocarbon in Jiaozhou Bay waters [J]. Applied Mechanics and Materials Vols.644-650. 2014, 5312-5315.

4. Dongfang Yang, Youfu Wu, Huozhong He, Sixi Zhu and Fengyou Wang. Vertical distribution of Petroleum Hydrocarbon in Jiaozhou Bay [J]. Proceedings of the 2015 international symposium on computers and informatics. 2015, 2647-2654.

5. Dongfang Yang, Fengyou Wang, Sixi Zhu, Xiaoli Zhao and Jiaolian Luo. Distribution and homogeneity of petroleum hydrocarbon in Jiaozhou Bay $[\mathrm{J}]$. Proceedings of the 2015 international symposium on computers and informatics. 2015, 2661-2666.

6. Dongfang Yang, Peiyan Sun, Lian Ju, Qingyun Yu and Jing Cao. Input features of Petroleum Hydrocarbon in Jiaozhou Bay[J]. Proceedings of the 2015 international symposium on computers and informatics. 2015, 2675-2680.

7. YANG D F, CHEN Y, GAO Z H, et al. Silicon Limitation on primary production and its destiny in Jiaozhou Bay, China IV transect offshore the coast with estuaries [J]. Chin. J. Oceanol. Limnol. 2005, 23(1): 72-90.

8. Dongfang Yang, Fan Wang, Zhenhui Gao, et al. Ecological Phenomena of Phytoplankton in Jiaozhou Bay [J]. Marine Science, 2004, 28 (6): 71-74.

9. State Oceanic Administration. The Specification for Marine Monitoring [Z]. Beijing: China Ocean Press, 1991. 